\title{
DESEMPENHO DE CORDEIROS SANTA INÊS SUBMETIDOS A ALEITAMENTO ARTIFICIAL ENRIQUECIDO COM Spirulina platensis
}

\author{
Leilson Rocha Bezerra, ${ }^{1}$ Aderbal Marcos Azevedo Silva, ${ }^{2}$ Solange Absalão Azevedo, ${ }^{3}$ \\ Rodrigo Souza Mendes, ${ }^{4}$ Júlia Mary Mangueira ${ }^{4}$ e Anny Kaline Andrade Gomes ${ }^{4}$ \\ 1. Doutorando em Zootecnia UFPB. E-mail: leilsonbezerra@yahoo.com.br \\ 2. Professor doutor, Departamento de Medicina Veterinária, UFCG \\ 3. Professora doutora, Departamento de Medicina Veterinária, UFCG \\ 4. Graduando de Medicina Veterinária UFCG.
}

\section{RESUMO}

O experimento foi desenvolvido no Setor de Ovinocultura pertencente à Fazenda Maria Paz, localizada no município de São José de Espinharas, PB, e no Laboratório de Nutrição Animal (LANA) do Centro de Saúde e Tecnologia Rural da Universidade Federal de Campina Grande. Avaliou-se o efeito da suplementação em creep feeding com leite bovino enriquecido com Spirulina platensis (espirulina) e concentrado no desempenho de cordeiros da raça Santa Inês, mediante o consumo de matéria seca (CMS), consumo de proteína bruta (CPB), peso corporal (PC), ganho de peso médio diário (GPMD), e estimou-se o período da fase de aleitamento mais adequada para a utilização da espirulina. Distribuíram-se trinta cordeiros em um delineamento em blocos ao acaso, testando três níveis de espirulina nas parcelas principais, com parcelas subdivididas no tempo. Não houve efeito de interação do nível de espirulina administrado e os períodos consecutivos, e o efeito dos períodos no consumo foi independente, com o consumo aumentando em função da idade dos animais. Quanto ao peso no final de cada período e ganho de peso médio diário, houve efeito de interação do nível de espirulina e os períodos estudados. O nível de espirulina teve efeito no GPMD apenas dentro dos primeiros quinze dias, com maior ganho para o nível de $10 \mathrm{~g}$ de espirulina (300 g) em relação à testemunha $(205 \mathrm{~g})$. $\mathrm{O}$ peso corporal final foi maior para o tratamento com $10 \mathrm{~g}$ de espirulina em todos os períodos estudados (12,0; 17,02; 19,71 e 25,30kg). A diluição de Spirulina platensis no leite bovino se mostrou eficiente no desempenho diário de cordeiros quando utilizada na concentração de $10 \mathrm{~g}$ diárias e no período entre quinze e trinta dias de idade.

PALAVRAS-CHAVES: Alimentação, epirulina, leite, ovinos.

\section{PERFORMANCE OF SANTA INÊS LAMBS SUBMITTED TO THE USE OF ARTIFICIAL MILK ENRICHED WITH Spirulina platensis}

The experiment was carried out in Maria Paz Ranch/Sheep Production Department, in São José de Espinharas, PB. Analyses were performed in the Laboratory of Animal Nutrition/Centro de Saúde e Tecnologia Rural/Universidade Federal de Campina Grande. The objectives of this study were to evaluate the effect of the supplementation with cow milk enriched with Spirulina platensis $(\mathrm{Sp})$ on lamb performance submitted to creep feeding, and determine the most adequate period to suplemet nursing lambs with Spirulina platensis. Data on dry matter (DMC) and crude protein (CPC) consumptions, body weight (BW), and mean daily body weight gain (MDBWG) were colleted. The three levels of Spirulina supplementation were assigned to 30 lambs (plots) according to a randomized block (lamb weight) design with 10 replications. Data were collected in four consecutive periods, characterizing a split plot in time. DM and CP consumptions were not affected by Spirulina level x period interaction, and increased with periods (animal age). BW and MDBWG were affected by the spirulina level x period interaction. Spirulina levels affected MDBWG only from day 0 to day 15, when the MDBWG (300g) was higher at level $10 \mathrm{~g}$ than at level zero of Spirulina that resulted 
in 205g in MDBWG. Live body weight at the end of each period was also higher when the lambs were supplemented with $10 \mathrm{~g}$ of Spirulina (12.00 17.02, 19.71 and $25.30 \mathrm{~kg}$, respectively, for the four consecutive periods). The dilution of Spirulina platensis in

KEYWORDS: Feed, milk, sheep, Spirulina platensis.

\section{INTRODUÇÃO}

A importância dos ovinos como fonte de alimentos proteicos para regiões em desenvolvimento tem sido enfatizada ao longo das últimas décadas. A produção de carne representa hoje uma atividade socioeconômica em crescimento que vem se firmando, cada vez mais, como alternativa para pequena e média propriedade rural, considerando a sua exploração utilizando a mão de obra familiar e instalações simples e de baixo custo.

A demanda pela carne ovina concentra-se em cordeiros com peso de $28 \mathrm{~kg}$ ao abate, o que tem sido adotado como o mais adequado para o atual mercado consumidor brasileiro, segundo diversos autores (SILVA\& PIRES, 2000; NERES et al., 2001). A exploração dessa categoria se explica pelo fato de ser a que fornece carne de melhor qualidade e apresenta os maiores rendimentos de carcaça e eficiência de produção, em consequência de sua alta velocidade de crescimento (BUENO et al., 2000).

A introdução de raças de corte precoces e o uso de estratégias de suplementação alimentar são recursos frequentemente recomendados pelos técnicos, na busca pela diminuição da idade ao abate, pela melhoria da qualidade de carcaça e, consequentemente, por melhores resultados econômicos, opondo-se aos sistemas tradicionais de terminação a pasto (MACEDO et al., 2000; SIQUEIRA \& FERNANDES, 2000).

O aleitamento artificial é um tipo de manejo que permite a separação do cordeiro de sua mãe logo após o nascimento e pode ser utilizado para diferentes fins, tendo como vantagens o controle das mamadas e o retorno mais rápido da ovelha à vida reprodutiva (CHURCH, 1993). Outra estratégia comumente utilizada é o creep feeding, cujo objetivo é viabilizar a disponibilidade de concentrado aos cordeiros. A utilização de comedouros seletivos (creep feeding) é uma valiosa ferramenta para obtenção de bons resultados zootécnicos e econômicos, permitindo o abate precoce cow milk showed to be efficient on the daily performance of lambs when utilized in concentration of $10 \mathrm{~g} /$ day and from period 15 to 30 days of age.

dos animais com maior taxa de desfrute do rebanho ovino nacional (NERES et al., 2001).

É comum a busca de fontes de nutrientes que completem as exigências desses animais, principalmente na fase de crescimento, em que a exigência é ainda maior, como a utilização de probióticos, suplementos vitamínicos (A, D, E) sintéticos, entre outros. Porém, nem sempre essa prática de manejo é satisfatória, já que se trata de uma fonte não natural, além de encarecer a produção. Diante da inovação tecnológica, tem se buscado meios naturais para as produções, tornando os produtos essencialmente orgânicos mais requisitados no mercado.

Em países como o México, Estados Unidos e Japão, a Spirulina platensis, uma cianobactéria filamentosa que habita meios como solos, pântanos, lagos alcalinos e águas salobras, marinhas e doces e que, por intermédio de fotossíntese, converte os nutrientes em matéria celular e libera oxigênio, tem sido usada na alimentação humana, pela sua alta composição vitamínico-mineral, não sendo comum sua utilização na produção animal (TESKE \& TRENTINI, 2001).

O teor de proteína da espirulina oscila entre $50 \%$ e 70\% de sua matéria seca. Levando em consideração o fator qualitativo, a proteína da espirulina é completa, pois contém todos os aminoácidos essenciais e não essenciais. Embora dez gramas de espirulina (10S) representem apenas $6 \mathrm{~g}$ de proteína, na fase 0 -quinze dias estes seis gramas representam cerca de $12 \%$ da proteína ingerida. Alguns trabalhos verificaram maior ganho de peso quando se aumenta o CPB na ração (MUWALA et al., 1998; TITI et al., 2000). Outra característica importante é que a espirulina é facilmente digerida, pois sua parede celular é composta de mucopolissacarídeos, açúcares simples e proteínas, o que a diferencia de outras algas que possuem celulose. Essas características reforçam a maior eficiência de utilização dos cordeiros na fase inicial de vida dos animais, quando seu organismo funciona como um não ruminante. 
Para MULLER et al. (2002), no estabelecimento da ovinocultura de corte é necessário introduzir animais eficientes no sistema de produção, os quais devem ser portadores de características desejáveis para a obtenção de carcaças de qualidade superior, de acordo com as exigências de mercado, a fim de que se estabeleça o hábito de consumo. $\mathrm{O}$ acabamento em confinamento deve ser iniciado quando os animais atingem peso corporal mínimo de $15 \mathrm{~kg}$, com a duração de 56 a 70 dias, e dentre as raças ovinas predominantes no Nordeste, a raça Santa Inês é a que obtém os melhores ganhos de peso em confinamento, podendo ganhar $267 \mathrm{~g}$ por dia (ALMEIDA Jr. et al., 2004; FURUSHO-GARCIA et al., 2004).

O objetivo deste trabalho foi avaliar o efeito da suplementação da dieta de cordeiros Santa Inês confinados enriquecida com Spirulina platensis.

\section{MATERIAL E MÉTODOS}

O experimento foi desenvolvido no setor de ovinocaprinocultura, pertencente à Fazenda Maria Paz, localizada no município de São José de Espinharas, $\mathrm{PB}$, e as análises químicas dos alimentos realizadas no Laboratório de Nutrição Animal do Centro de Saúde e Tecnologia Rural da Universidade Federal de Campina Grande. Utilizaram-se trinta cordeiros puros da raça Santa Inês, filhos de mesmo pai e oriundos de um programa de inseminação artificial e transferência de embriões, com peso médio inicial de $6,9 \pm 0,8 \mathrm{~kg}$ e idade média inicial de $17 \pm 4$ dias. Adotou-se delineamento em blocos ao acaso, com parcelas subdivididas no tempo, que consistiu na administração diária de espirulina (oriunda da Fazenda Tamanduá, município de Santa Terezinha, PB) em três concentrações $(0,5$ e $10 \mathrm{~g})$, em quatro períodos consecutivos $(0-15,15-30$, 30-45 e 45-60 dias). A duração do período experimental foi de oito semanas, com um período pré-experimental de oito dias para adaptação dos animais às dietas e às instalações. Nesse período os animais foram vacinados e everminados. Procedeu-se à avaliação do desenvolvimento dos animais por meio de pesagens realizadas em intervalos de quinze dias, após jejum prévio de doze horas, antes do fornecimento da ração, às $7 \mathrm{~h}$.

A dieta dos animais foi composta de leite materno, aleitamento artificial enriquecido ou não com espirulina, concentrado e feno de Tifton. A composi- ção química dos ingredientes utilizados na dieta dos animais está apresentada na Tabela 1.

TABELA 1. Composição químico-bromatológica dos ingredientes da dieta (\% MS)

\begin{tabular}{lccccc}
\hline \multicolumn{1}{c}{ *Ingrediente } & MS (\%) & PB (\%) & EE (\%) & Ca (\%) & P (\%) \\
\hline Leite de vaca & 12,75 & 25,75 & 28,2 & 1,03 & 0,81 \\
Spirulina platensis & 87,67 & 65,32 & 1,27 & 1,62 & 0,54 \\
Concentrado & 90,56 & 22,10 & 4,39 & 1,44 & 0,49 \\
Feno de Tifton & 90,83 & 8,56 & 2,62 & 1,62 & 0,54 \\
\hline
\end{tabular}

*MS, matéria seca; $\mathrm{PB}$, proteína bruta; $\mathrm{EE}$, extrato etéreo; $\mathrm{Ca}$, cálcio e $\mathrm{P}$, fósforo.

O concentrado, à base de milho (62\%), farelo de soja $(33 \%)$, fosfato bicálcico $(1,8 \%)$, calcário calcítico $(2,2 \%)$ e núcleo mineral $(1,0 \%)$, foi ajustado de modo $a$ atender às recomendações do ARC (1980) para ganho médio diário de $250 \mathrm{~g} / \mathrm{dia}$. Apenas após o trigésimo dia de experimento foi disponibilizado feno de Tifton, $a d$ libitum, para os animais. A alimentação era fornecida à vontade, duas vezes ao dia, prevendo-se uma sobra de $30 \%$. Amostras de espirulina, concentrado, feno e leite foram colhidas e posteriormente encaminhadas ao Laboratório de Nutrição Animal (LANA) para análises segundo metodologia descrita por SILVA \& QUEIROZ (2002), objetivando a determinação dos teores de matéria seca, proteína bruta, extrato etéreo, cálcio e fósforo. Durante a fase experimental, os animais permaneceram por todo o dia em baias coletivas com piso de terra batida, cobertas com telhas de cerâmica, dotadas de comedouros e bebedouros coletivos. Nesse período, os animais recebiam aleitamento artificial (leite bovino in natura ou enriquecido com espirulina), em duas mamadas por dia, através do qual foi administrada a espirulina, além de mistura concentrada e feno à vontade. Ao entardecer, os cordeiros tinham acesso ao curral das mães, que possuía as mesmas características das baias, e pernoitavam em um sistema de creep-feeding, onde tinham acesso à mistura de concentrado.

Avaliaram-se as seguintes variáveis: CMS, correspondendo ao consumo médio de matéria seca (concentrado + feno); CMSL, ao consumo médio de matéria seca do leite (leite de vaca enriquecido ou não); $\mathrm{CPB}$, ao consumo médio de proteína bruta (concentrado + feno); e CPBL, ao consumo médio de 
proteína bruta do leite (leite de vaca enriquecido ou não). Efetuou-se diariamente o controle da ingestão das dietas experimentais. $\mathrm{O}$ ganho de peso médio diário GPMD (g/dia) foi calculado mediante pesagens dos animais a cada quinze dias.

As variáveis foram submetidas à análise de variância por meio do procedimento PROC GLM (General Linear Models) do SAS (1999) e os contrastes entre médias pelo teste de Tukey, ao nível de $5 \%$ de probabilidade, através do seguinte modelo estatístico: $\mathrm{Y}_{\mathrm{ijk}}=\mu+\mathrm{s}_{\mathrm{i}}+\mathrm{b}_{\mathrm{j}}+(\mathrm{sb})_{\mathrm{ij}}+\mathrm{s}_{\mathrm{k}}{ }+\mathrm{ss}^{\prime}{ }_{\mathrm{ik}}+\mathrm{e}_{\mathrm{ijk},}$ em que: Yi j $\mathrm{k}$ são os valores observados de cada variável no nível i de concentração de espirulina e o nível j de período de administração, na repetição $\mathrm{k}(\mathrm{k}=1,2,3,4,5,6) ; \mu$ a média geral; si o efeito do nível i de concentração de espirulina $(i=0,5$ e $10 \mathrm{~g})$; bj o efeito do nível $\mathrm{j}$ do período $(\mathrm{j}=)$; $(\mathrm{sb}) \mathrm{i}$ j o efeito da interação dos fatores espirulina e período de administração; $\mathrm{s}_{\mathrm{k}}{ }_{\mathrm{k}} \mathrm{o}$ efeito do nível de tratamento; ss ${ }_{i k}$ o efeito da interação; ( i j) k o erro experimental. Para corrigir possível efeito do peso inicial dos animais sobre as variáveis analisadas nos tratamentos, empregou-se como covariância o peso inicial dos animais, objetivando redução do erro residual.

\section{RESULTADOS E DISCUSSÃO}

Os dados obtidos no experimento relacionado ao consumo alimentar (g/dia) dos animais em função dos períodos estão expressos na Tabela 2. Não houve efeito de interação entre os níveis de espirulina na dieta dos animais e os períodos de administração estudados.

TABELA 2. Valores do consumo médio de matéria seca (CMS), matéria seca do leite (CMSL), proteína bruta (CPB) e proteína bruta do leite $\mathrm{CPBL}$ em função dos períodos estudados

\begin{tabular}{lcccc}
\hline \multirow{2}{*}{ Vaviáveis } & \multicolumn{4}{c}{ Períodos } \\
\cline { 2 - 5 } & $\begin{array}{c}\text { (0-quinze } \\
\text { dias) }\end{array}$ & $(15-30$ dias) & $(30-45$ dias $)$ & $(45-60$ dias $)$ \\
\hline CMSL (g/dia) & $69,4^{\mathrm{D}}$ & $89,0^{\mathrm{C}}$ & $167,6^{\mathrm{B}}$ & $233,3^{\mathrm{A}}$ \\
CMS (g/dia) & $99,6^{\mathrm{D}}$ & $178,2^{\mathrm{C}}$ & $485,1^{\mathrm{B}}$ & $711,5^{\mathrm{A}}$ \\
CPBL (g/dia) & $31,6^{\mathrm{D}}$ & $39,5^{\mathrm{C}}$ & $73,8^{\mathrm{B}}$ & $95,6^{\mathrm{A}}$ \\
CPBS (g/dia) & $15,8^{\mathrm{D}}$ & $19,6^{\mathrm{C}}$ & $38,2^{\mathrm{B}}$ & $53,1^{\mathrm{A}}$ \\
\hline
\end{tabular}

Médias seguidas da mesma letra na linha não diferem entre si pelo teste de Tukey $(\mathrm{P}<0,05)$.
Em análise dos fatores principais, observouse que não houve efeito dos níveis de espirulina na ingestão média diária dos nutrientes, seja na forma sólida ou líquida $(\mathrm{P}>0,05)$. $\mathrm{O}$ consumo médio diário estimado de MS (CMS +CMSL) e PB (CPB + CPBL) observado nos respectivos períodos foi de: (0-15), 169 e 47,4 g; (15-30), 267,4 e 59,1 g; (30-45), 625,7 e $112 \mathrm{~g}$; (45-60 dias), 944,8 e 148,7 g. No presente experimento, na primeira semana de vida, os cordeiros dependeram exclusivamente do leite das ovelhas. Este fato é importante, pois nessa idade ocorre a ingestão de colostro, que é fundamental para o sistema imunológico do animal. Após esse período, a suplementação, primeiramente com concentrado de alta digestibilidade e a partir do trigésimo dia com volumosos de boa qualidade, estimulou o desenvolvimento precoce do rumem e aumentou a taxa de crescimento dos animais. Os dados relativos ao peso vivo (PV) e ao ganho de peso médio diário (GPMD) dos animais estão apresentados na Tabela 3. Pode-se observar que os efeitos dos níveis de espirulina na dieta não foram independentes, havendo interação com o período administrado.

TABELA 3. Peso vivo e ganho de peso médio diário de cordeiros lactentes em função dos níveis de espirulina (S) e da idade (dias)

\begin{tabular}{|c|c|c|c|}
\hline Períodos & $0 \mathrm{gS}$ & $5 \mathrm{gS}$ & $10 \mathrm{gS}$ \\
\hline \multicolumn{4}{|c|}{ Peso vivo(Kg) } \\
\hline P15 dias & $9,90^{\mathrm{dB}}$ & $11,02^{\mathrm{dAB}}$ & $12,00^{\mathrm{dA}}$ \\
\hline P30 dias & $14,80^{\mathrm{cB}}$ & $16,96^{\mathrm{cbAB}}$ & $17,02^{\mathrm{cA}}$ \\
\hline P45 dias & $17,92^{\mathrm{bB}}$ & $18,67^{\mathrm{bAB}}$ & $19,71^{\mathrm{bA}}$ \\
\hline P60 dias & $22,47^{\mathrm{aB}}$ & $23,12^{\mathrm{aB}}$ & $25,30^{\mathrm{aA}}$ \\
\hline \multicolumn{4}{|c|}{ Ganho de peso médio diário (g/dia) } \\
\hline $0-15$ dias & $205^{\mathrm{bB}}$ & $262^{\mathrm{bAB}}$ & $300^{\mathrm{aA}}$ \\
\hline $15-30$ dias & $326^{\mathrm{aA}}$ & $329^{\mathrm{aA}}$ & $335^{\mathrm{aA}}$ \\
\hline $30-45$ dias & $208^{\mathrm{bA}}$ & $180^{\mathrm{cA}}$ & $202^{\mathrm{bA}}$ \\
\hline $45-60$ dias & $303^{\mathrm{aA}}$ & $297^{\mathrm{aA}}$ & $350^{\mathrm{aA}}$ \\
\hline
\end{tabular}

Médias seguidas da mesma letra minúscula na coluna e maiúscula na linha não diferem entre si pelo teste de Tukey $(\mathrm{P}<0,05)$;

$0 \mathrm{gS}=$ animais que recebiam apenas o aleitamento artificial com leite de vaca;

$5 \mathrm{gS}=$ animais que recebiam $5 \mathrm{~g}$ de Spirulina platensis diluída em leite de vaca;

$10 \mathrm{gS}=$ animais que recebiam $10 \mathrm{~g}$ de Spirulina platensis diluída em leite de vaca. 
Em análise do efeito dos níveis de espirulina dentro dos períodos estudados, observa-se que apenas no período de 0 a 15 dias experimentais o aumento do nível de espirulina na dieta dos animais proporcionou maior ganho de peso em relação à testemunha. Contudo, em relação ao PV o tratamento com $10 \mathrm{gS}$ proporcionou maior peso em todos os períodos analisados, diante da testemunha, e esta não diferiu quanto ao $\mathrm{PV}$ do tratamento com $5 \mathrm{gS}(\mathrm{P}<0,05)$.

A diferença no GPMD dos cordeiros apenas no período de zero a quinze dias provavelmente tenha ocorrido em virtude de os animais, nesta fase inicial de aleitamento, apresentarem maior eficiência no aproveitamento dos nutrientes contidos no leite (SILVA SOBRINHO, 1997). Quanto ao maior PV dos animais cujo tratamento foi com $10 \mathrm{gS}$, em relação à testemunha, em todos os períodos, isso provavelmente se deve ao efeito acumulativo dos GPMD, que, embora não significativo nos períodos subsequentes aos de zero e quinze, apresentaram significância ao nível $(\mathrm{P}<0,13)$. Sabe-se que a espirulina é considerada um dos alimentos naturais que possui o maior conteúdo de proteínas da natureza, com todos os aminoácidos essenciais, sendo fundamental para a produção de certas substâncias que atuam como fatores de crescimento (BABU, 1995).

No período de zero e trinta dias de experimento, não foi observada diferença significativa $(\mathrm{P}>0,05)$ entre os grupos para o GPMD. Porém houve diferença estatística significativa $(\mathrm{P}<0,05)$ entre os grupos que consumiam espirulina $(5 \mathrm{gS}$ e $10 \mathrm{gS})$ e os que consumiam apenas leite de vaca $(0 \mathrm{gS})$ para o PV dos cordeiros. Aos 45 dias, a suplementação de espirulina não proporcionou diferença significativa $(\mathrm{P}>0,05)$ entre os grupos experimentais para o GPMD. MULLER et al. (2006) não observaram diferença significativa $(\mathrm{P}>0,05)$ para ganho médio diário do nascimento ao desmame, ganho médio diário do desmame ao abate de cordeiros em confinamento. Entretanto o PV dos animais suplementados com $10 \mathrm{~g}$ diferiu estatisticamente dos demais grupos $(0 \mathrm{gS}$ e $5 \mathrm{gS})$ tanto aos 45 dias como também ao final do experimento. PIRES et al. (2000) observaram, em cordeiros Texel confinados e desmamados aos 45 dias, peso ao desmame de 19,94 kg, valor semelhante ao grupo $10 \mathrm{gS}$ do presente estudo. Entretanto, esses valores são superiores ao observado por MOTTA
(2000), que verificou para cordeiros da raça Texel em confinamento, desmamados aos 45 e 60 dias e com acesso ao creep-feeding, peso ao desmame de 13,39 e $15,58 \mathrm{~kg}$, respectivamente.

No período de 45 dias observa-se uma redução do GPMD de todos os grupos. Isto se explica por coincidir com o período em que a ovelha tem uma queda brusca na produção de leite, sendo considerada a idade ideal para o desmame (SILVA SOBRINHO, 1997). SILVA et al. (2002), avaliando a contribuição do leite no crescimento de cordeiros suplementados em creep-feeding comparados aos cordeiros não suplementados, concluíram que a contribuição do leite no ganho de peso dos cordeiros foi fundamental até o pico de lactação das ovelhas (três a quatro semanas) e destacaram o papel da suplementação alimentar, principalmente, após o primeiro mês de vida dos cordeiros. A alimentação balanceada na época do aleitamento aumenta o ritmo de crescimento, reduz a mortalidade e evita restrições na produção futura do animal (SILVA SOBRINHO, 1997). Outro fator importante para promover redução no ganho de peso foi a introdução do feno de Tifton, provocando, assim, uma mudança na alimentação dos animais. A época do desmame influencia no desempenho precoce do animal e, com o passar da idade, as taxas de ganhos diários de peso vivo serão menores, pois maior é o estresse sofrido pelos cordeiros no desmame (SILVA SOBRINHO, 1997).

Não houve diferença significativa $(P>0,05)$ no GPMD dos animais ao final deste experimento. O maior GPMD foi obtido pelo grupo 10S (350g), superando os valores obtidos por MULLER et al. (2006), em um sistema de criação de cordeiros para abate superprecoce, em que os animais apresentaram ganhos de peso de $280 \mathrm{~g}$ diários. Esses autores relataram que, para a produção de animais superprecoces, o ganho de peso individual em confinamento deve ser ao redor de 200 a $300 \mathrm{~g} / \mathrm{dia}$, para que os animais cheguem rapidamente ao peso de abate. Os valores obtidos neste experimento também foram semelhantes aos encontrados por SANTOS (2000), ALMEIDA JÚNIOR et al. (2004) e FURUSHO-GARCIA et al. (2004), com ganhos de peso respectivos de 261, 291, $396 \mathrm{~g} / \mathrm{dia}$, trabalhando com o fornecimento de dietas para cordeiros Santa Inês em confinamento para abate precoce. 


\section{CONCLUSÃO}

Os dados de desempenho do presente experimento mostram que a diluição de Spirulina platensis no leite bovino se mostrou eficiente no melhoramento do desempenho de cordeiros quando usada na concentração de $10 \mathrm{~g}$ diárias e que os primeiros trinta dias de vida parecem constituir o melhor intervalo para sua utilização, quando o rúmen ainda não está totalmente desenvolvido e o funcionamento do organismo assemelha-se a um não ruminante.

\section{AGRADECIMENTOS}

Aos proprietários das Fazendas Tamanduá e Maria Paz, pelos serviços prestados.

\section{REFERÊNCIAS}

AGRICULTURAL RESEARCH COUNCIL. ARC. The nutrient requirements of farm livestock. London, 1980. 351 p.

ALMEIDA JÚNIOR, G. A.; COSTA, C.; MONTEIRO, A. L. G.; GARCIA, C. A.; MUNARI, D. P.; NERES, M. A. Desempenho, características de carcaça e resultado econômico de cordeiros criados em creep feeding com silagem de grãos úmidos de milho. Revista Brasileira de Zootecnia, v. 33, n. 4, p. 1048-1059, 2004.

BABU M. Evaluation of chemoprevention of oral cancer with Spirulina fusiformis. Nutrition Cancer, v. 24, p. 197-202, 1995

BUENO, M. S.; CUNHA, E. D.; SANTOS, L. E.; RODA, D. S; LEINZ, F. F. Características de carcaça de cordeiros Suffolk abatidos em diferentes idades. Revista Brasileira de Zootecnia, v. 29, n. 6, p. 1803-1810, 2000.

CHURCH, D. C. El rumiante fisiológia digestiva y nutrición. Zaragoza: Acribia, 1993. 641 p.

FURUSHO-GARCIA, I. F.; PEREZ, J. R. O; BONAGURIO, S.; ASSIS, R. M.; PEDREIRA, B. C.; SOUZA, X. R. Desempenho de cordeiros Santa Inês puros e cruzas de Santa Inês com Texell, Ille de France e Bergamácea. Revista Brasileira de Zootecnia, v. 33 , n. 6, p. 1591-1603, 2004.

MACEDO, F. A. F.; SIQUEIRA, E. R.; MARTINS, E. N.; MACEDO, R. M. G. Qualidade de carcaças de cordeiros Corriedale, Bergamácia x Corriedale e Hampshire Down x Corriedale, terminados em pastagem e confinamento. Revista Brasileira de Zootecnia, v. 29, n. 5, p. 1520-1527, 2000.

MOTTA, O. S. Ganho de peso, características da carcaça de cordeiros(a) em diferentes métodos de alimentação, pesos de abate $\mathrm{e}$ produção de leite das ovelhas. Santa Maria, 2000. 76 f. Dissertação(Mestrado em Zootecnia) - Universidade Federal de Santa Maria, 2000.
MÜLLER, L.; PIRES, C. C.; TONETTO, C. J.; VOLLENHAUPT, L. S.; MEDEIROS, S. L. P. Efeito do desmame precoce em cordeiros cruzas Ile de France x Texel no desempenho e nas características da carcaça. Revista Ciência Agronômica, v. 37, n. 2, p. 241-245, 2006.

MUWALA, M. M.; HARB, M. Y.; CROSBY, T. F. Effects of lasloeid and protein levels on the performance of Awassi lambs. Small Ruminant Research, v. 28, p. 15-22, 1998.

NERES, M. A.; GARCIA, C. A.; MONTEIRO, A. L. G.; COSTA, C.; SILVEIRA, A. C.; ROSA, G. J. M. Níveis de feno de alfafa e forma física da ração no desempenho de cordeiros em creep feeding. Revista Brasileira de Zootecnia, v. 30, n. 3, p. 941-947, 2001.

PIRES, C. C.; SILVA, L. F.; SCHLICK, F. E.; GUERRA, D. P.; BISCAINO, G.; CARNEIRO, R. M. Cria e terminação de cordeiros confinados. Ciência Rural, v. 30, n. 5, p. 875-880, 2000.

SANTOS, Y. C. C. Composição corporal e exigências nutricionais de energia e proteína de cordeiros Bergamácia dos 35 aos $45 \mathrm{~kg}$ de peso vivo. 2000. $63 \mathrm{f}$. Tese (Mestrado em Zootecnia) - Universidade Federal de Lavras, Lavras, 2000.

SILVA SOBRINHO, A. G. Criação de ovinos. Jaboticabal: FUNEP, 1997. $230 \mathrm{p}$.

SILVA, D. J.; QUEIROZ, A. C. Análise de alimentos: métodos químicos e biológicos. 3. ed. Viçosa: Universidade Federal de Viçosa, 2002. 235 p.

SILVA, J. J.; COSTA, C.; MONTEIRO, A. L. G.; GARCIA, C. A.; CROCCIS, A. J. Contribuição do leite de ovelhas Suffolk no desempenho dos cordeiros, em dois sistemas de produção. In: REUNIÃO ANUAL DA SOCIEDADE BRASILEIRA DE ZOOTECNIA, 39., 2002, Recife. Anais... Recife: Sociedade Brasileira de Zootecnia/ Technomedia, [2002]. CD-ROM. Manejo e Reprodução. 03sbz0190. pdf.

SILVA, L. F.; PIRES, C. C. Avaliações quantitativas e predição das proporções de osso, músculo e gordura da carcaça em ovinos. Revista Brasileira de Zootecnia, v. 29, n. 4, p. 1253-1260, 2000.

SIQUEIRA, E. R.; FERNANDES, S. Efeito do genótipo sobre as medidas objetivas e subjetivas da carcaça de cordeiros terminados em confinamento. Revista Brasileira de Zootecnia, v. 29, n. 1, p. 306-311, 2000.

STATYSTICALANALYSIS SYSTEMS. SAS. User's Guide: North Caroline: SAS Institute. INC, Cary, 1999.

TESKE, M.; TRENTINI, A. M. M. Herbarium: compêdio de ficoterapia. Curitiba: Herbarium, 2001. 317 p.

TITI, H. H.; TABBAA, M. J.; AMASHEH, M. G.; BARAKEH, F.; DAQAMSEH, B. Comparative performance of Awassi lambs and Black goats kids on different, crude protein levels in Jordan. Small Ruminant Research, v. 37, p. 131-135, 2000. 